\title{
AVALIAÇÃO DO MODELO DE EXCELÊNCIA DE GESTÃO APLICADA EM UMA CONCESSIONÁRIA DE VEÍCULOS
}

\author{
EXCELLENCE MANAGEMENT MODEL ASSESSMENT IN A CAR DEALER
}

Recebido: 22/12/2014 - Aprovado: 06/04/2015 - Publicado: 15/05/2015
Processo de Avaliação: Double Blind Review

Flávio Romero Macau

Doutor em Estratégia de Operações

Coordenador do Programa de Mestrado Acadêmico em Administração Universidade Paulista - UNIP

Eduardo Fernando Mendes

Doutorando em Ciência da Computação

Universidade Paulista - UNIP

Mauro Manoel Quaio Posso ${ }^{1}$

Graduando em Administração de Empresas

Universidade Paulista - UNIP

\section{RESUMO}

O artigo explora a avaliação do desempenho e da qualidade da gestão aplicada em uma concessionária de veículos. Sua base são os critérios do Modelo de Excelência de Gestão da Fundação Nacional de Qualidade, colocados em prática numa autoavaliação que envolve as operações e procedimentos da empresa. O preenchimento do questionário define uma pontuação de referência e estimula a busca dos motivos e as ações para o aprimoramento em cada item.

Palavras-chave: Excelência em Gestão; Fundação Nacional da Qualidade; Concessionária de Veículos.

\section{ABSTRACT}

This paper explores the evaluation of performance and quality management in a car dealer. The evaluation is based on the Excellence Model in Management criteria from the FNQ Foundation, measured through a self assessment of the firm operations and procedures. The analysis of the responses result in a reference score, and stimulates the development of ideas and directives to enhance each criteria.

Key-words: Excellence Management; National Quality Foundation; Car Dealers.

\footnotetext{
${ }^{1}$ Autor para correspondência: Universidade Paulista- UNIP

Rua Bacelar 1212- bairro V1. Clementino - São Paulo -SP, 04026-002. mauroposso@ hotmail.com
} 


\section{INTRODUÇÃO}

As mudanças constantes nas demandas da sociedade e no perfil dos clientes, a evolução da tecnologia e o aumento da competitividade tem exigido alto desempenho das empresas. Com a globalização, quebra de barreiras e encurtamento de fronteiras, os desafios tornam-se cada vez maiores. Em resposta a este cenário, as empresas tem buscado a melhoria de seus processos e resultados, implementando modelos e ferramentas gerenciais com o objetivo de se tornarem cada vez mais competitivas. Neste contexto, o Modelo de Excelência em Gestão da Fundação Nacional da Qualidade (FNQ) mostra-se como importante instrumento de gestão que visa orientar como uma empresa deve ser gerenciada de forma sistêmica, com o intuito de conduzi-la ao alto desempenho.

No que diz respeito às mudanças estruturais nas organizações, o foco principal de uma organização passou a ser o conhecimento e a capacidade de se adaptar a novas situações, ou seja, a flexibilidade de sua estrutura organizacional e a rapidez de suas decisões. As estruturas tendem a ser mais enxutas e flexíveis, e o relacionamento interfuncional se torna mais relevante. As principais fontes de sustentação e diferenciação da estratégia de uma organização também mudaram. Em uma economia globalizada, as organizações têm acesso aos mesmos meios tecnológicos, aos mesmos processos industriais e as mesmas informações. O que as organizações mais competitivas e diferenciadas possuem são processos de gestão e as pessoas que dele fazem parte.

Nesta pesquisa, serão estudados, abordados e aplicados os conceitos do Modelo de Excelência em Gestão (MEG) da Fundação Nacional da Qualidade - FNQ, seguindo os Critérios de Excelência (liderança, estratégias e planos, clientes, sociedade, informações e conhecimento, pessoas, processos), acompanhados de um relatório de avaliação gerencial e de um conjunto de ações sugeridas, visando a melhoria de cada um deles. Estes critérios serão avaliados e testados com a finalidade de avaliar a eficiência das atividades da empresa objeto do estudo. Nos aspectos onde estes processos se mostrarem falhos, serão propostas ações visando melhores práticas de aplicação.

Durante o primeiro semestre de 2014 foi realizada uma pesquisa bibliográfica, principalmente aos manuais disponibilizados pela Fundação Nacional da Qualidade. Isso forneceu informações para o alcance do objetivo principal da pesquisa: identificar o nível de maturação do modelo de gestão das empresas do setor de concessionária de veículos, com base no Modelo de Excelência de Gestão (MEG).

\section{FUNDAMENTAÇÃO TEÓRICA}

"Os ambientes organizacionais têm se tornado menos benignos, mais complexos, mais inter-relacionados e mais dinâmicos". (MITROFF, 1988, apud GALBRAITH, 1995). Portanto, é importante para a sobrevivência das empresas que se tornem aprendizes eficientes, capazes de se adaptar à rápida alteração de condições em seu ambiente, gerando as melhorias 
que lhes permitirão sobreviver. A análise das condições organizacionais que promovem a melhoria requer forte integração, com forte cooperação entre áreas com responsabilidades diferentes, e orientação tanto para clientes internos quanto externos. O processo de melhoria deve ser visto como central, e apoiado como tal. São necessárias comunicações rápidas e simplificadas entre todos os níveis hierárquicos da empresa e compartilhamento de informações sobre o negócio, sua missão e seus objetivos.

\begin{abstract}
A identificação de áreas onde existem oportunidades para a melhoria de desempenho e a aplicação de processos de solução de problemas para efetuar melhorias são aspectos organizados de como as organizações aprendem. Em anos recentes, várias técnicas se tornaram relativamente comuns na organização. O feedback de pesquisa, por exemplo, é uma técnica de coleta de dados que se concentra nos esforços de solução de problemas em áreas onde existe um consenso geral de que a melhoria é necessária. (GALBRAITH, 1995, p. 75).
\end{abstract}

As empresas tem de buscar uma abordagem de qualidade total, com concentração de esforços no controle e na melhoria dos processos, utilizando ferramentas analíticas para identificar as causas das falhas, gerando soluções que tenham o maior impacto positivo possível sobre a qualidade, e focalizando as necessidades de clientes tanto internos e quanto externos (DEMING, 1986; JURAN, 1989). Na busca pelo alto desempenho as empresas estão sujeitas a grandes mudanças na maneira pela qual as operações são estruturadas e gerenciadas. Nos processos de mudança podem ocorrer alterações significativas nos valores que a empresa está tentando alcançar, nos papéis que as pessoas devem desempenhar, nas pressuposições e na visão global que governam o seu comportamento. Para Galbraith (1995), os principais conhecimentos sobre tais processos de mudança são:

- A mudança organizacional não ocorre a menos que haja um forte motivo. A razão para precisa estar ligada à estratégia da empresa, embora possa e deva ser acompanhada por uma orientação pessoal.

- A liderança é um fator crítico. A mudança não ocorre sem energia, orientação e comprometimento da alta cúpula.

- As empresas são sistemas nos quais a mudança em um aspecto exige mudanças em outros. O sistema é mais eficiente na medida em que seus vários componentes se encaixam. Muitos tipos de mudanças que as organizações enfrentam hoje em dia requerem alinhamento sistemático.

- A mudança envolve tanto os projetos técnicos como pessoas. Gerenciar a mudança envolve compreensão e saber lidar com a resistência, o aprendizado individual e coletivo, e com a dinâmica natural de transição.

- As alterações envolvem uma mudança na maneira pela qual as pessoas entendem a empresa. Haverá aqueles que não podem ou não querem fazer a transição, com algum turnover resultante.

- A mudança envolve tensão e conflito, consumindo energia. Não é ordeira nem controlada, pois envolve interações e surpresas. Embora possa ser parcialmente planejada, grande parte não o será.

- Parte da mudança exigirá o desenvolvimento de habilidades que a empresa não tem. 
No mundo de hoje as necessidades do cliente mudam, novos concorrentes entram a cada momento, e surgem novos materiais e tecnologias que levam à constante necessidade de questionar os processos de uma empresa (CAMPOS, 2013: pg. 166). A ideia de que a gestão da qualidade é traz resultados positivos para o negócio vem sendo sustentada desde os pioneiros do campo, como Deming, Juran, Ishikawa e Crosby (CORREA e CORREA, 2013). A visão acadêmica desses autores foi incorporada e colocada em prática, principalmente, pela indústria japonesa do pós-guerra, resultando em fenômenos de excelência como a Honda, Sony e Toyota. Concepções como as de Akio Morita, ícone da Sony, de que "O desafio maior para as empresas (...) está na gerência das novas tecnologias, novos desenvolvimentos e novos produtos" (MORITA, REINGOLD e SHIMOMURA, 1986: p. 266), ganharam força e dominaram o debate sobre a gestão nas empresas nas décadas de 1980 e 1990.

Motivados pelo avanço das ferramentas de gestão da qualidade surgiram entidades buscando parametrizar a excelência na gestão, estruturando o campo e fornecendo informações para o benchmark entre empresas, tais como o Prêmio Deming em 1951 no Japão, o Malcolm Baldrige National Quality Award em 1987 nos EUA, e o Prêmio Nacional da Qualidade em 1991. Para Oliveira e Martins (2008) os prêmios de excelência em qualidade e negócios refletem a maturidade com que a empresa alcança a produtividade e a qualidade em seus processos, garantindo o sucesso do negócio. Trata-se ao mesmo tempo de um reconhecimento e de uma oportunidade de melhoria, partindo principalmente da auto avaliação, realizada pelos próprios executivos e colaboradores da empresa.

Com o avanço das práticas, diversos estudos buscaram conectar o desempenho na gestão da qualidade com o sucesso das empresas são também conhecidos na literatura prática e acadêmica. Alguns exemplos são o realizado pelo General Accounting Office (EUA) em 1991, da American Society for Quality (ASQ) em 2005, e por Pignanelli (2006). Os resultados, ao relacionar o desempenho da empresa à excelência em gestão, não são convergentes. Há questões metodológicas, principalmente na dificuldade de isolar variáveis e seus efeitos. No entanto, emerge a percepção de que se a excelência em gestão não necessariamente traz uma vantagem competitiva sustentável para grandes empresas já bem estruturadas, ela pode ser bastante relevante:

\footnotetext{
"(...) para organizações com níveis ainda baixos de excelência na gestão e/ou para setores menos saturados e com menor grau de competição. Para esses casos, a adoção dos Critérios de Excelência pode ser vista até mesmo como um recurso estratégico, significando diferencial competitivo para pequenas e médias empresas" (PIGNANELLI, 2006)
}

Para Oliveira e Martins (2008) ao adotar um modelo de excelência em gestão com o do PNQ a empresa abre as portas para mudanças relevantes na mensuração do seu desempenho. Por um lado, a estruturação de alavancas externas de desempenho, por meio do desdobramento de objetivos (tais como num BSC) permitem que as estratégias, os clientes e a sociedade realmente sejam incorporados pela organização. Por outro lado, a estruturação de alavancas internas de desempenho, por meio de diagramas de gestão e a alteração da atitude e 
posicionamento das pessoas na empresa permitem que os processo caminhem para ideia de melhoria contínua. Os autores concluem que "com base nos casos estudados, a adoção do modelo de excelência do PNQ em grau diferente acabou exercendo um papel importante na evolução da medição de desempenho" (OLIVEIRA e MARTINS, 2008).

A característica principal do Prêmio Nacional de Qualidade é estruturar e alinhar componentes de gestão por uma ótica sistêmica, atestando excelência:

"O Modelo também possibilita a avaliação do grau de maturidade da gestão, pontuando processos gerenciais e resultados organizacionais. Proporciona, ainda, a compreensão do mercado e do cenário local ou global onde a empresa atua e se relaciona" (FNQ, 2014).

\section{Conforme a Fundação Nnacional de Qaulidade (2014):}

O modelo é baseado em 13 fundamentos: pensamento sistêmico; atuação em rede; aprendizado organizacional; inovação; agilidade; liderança transformadora; olhar para o futuro; conhecimento sobre clientes e mercados; responsabilidade social; valorização das pessoas e da cultura; decisões fundamentadas; orientação por processos; geração de valor. A mensuração ocorre pelo levantamento de evidências em torno de 8 critérios: liderança; estratégias e planos; clientes; sociedade; informações e conhecimento; pessoas; processos e resultados. Os resultados são o ponto de chegada e principal item de mensuração, medindo efetivamente o sucesso da organização. Sua conquista depende do atendimento das necessidades do cliente, para o qual as atividades devem estar orientadas, e onde agregar valor torna-se um componente chave. Outro grupo de interesse importante são a sociedade e as comunidades impactadas pela entrega dos bens ou serviços, o que envolve fatores como o cumprimento de leis e a sustentabilidade, tanto do negócio quanto ambiental.

Para atender a clientes e sociedade cabe ao líder disparar os processos na empresa, dado que as ações são iniciadas dentro de sua esfera de decisão. A liderança fornece o norte e controla as ações, formulando e impulsionando estratégias e planos de negócio para que estas se concretizem e levem aos resultados desejados. Um fator importante, nesse ponto, é o envolvimento das pessoas, no caso os colaboradores da empresa, para que exerçam suas funções com competência e motivação, buscando eficácia e eficiência em suas atividades dessa forma, entregando valor aos clientes. As pessoas trabalham em torno de processos que requerem melhoria contínua, tanto para incorporar inovações quanto para aprimorar pontos falhos, com redução de defeitos e desperdícios. Permeando esses elementos há a troca de informações e conhecimento, incorporados em rotinas do dia-a-dia, que permitem que a empresa evolua e execute consistentemente suas atividades e controles.

\section{METODOLOGIA DE PESQUISA}

Foi realizado um estudo de caso único de natureza explanatória (YIN, 2001), com o 
objetivo de observar a excelência de gestão de uma PME a partir do modelo da FNQ (2008). A abordagem foi qualitativa, envolvendo diversas interações com gestores escolhidos da firma em questão, tanto para resposta ao questionário quanto para verificação de evidência que consubstanciasse cada item. A empresa aspirante à melhoria de sua gestão foi a unidade de análise investigada, uma vez que nessa organização as práticas de gestão precisam ser aprimoradas. Por razões de confidencialidade não será possível apresentar diretamente a PME estudada, nem os sujeitos de pesquisa acompanhados na pesquisa.

Para o desenvolvimento do estudo de caso foi seguido o questionário estruturado do PNQ, a partir do software E-MEG Diagnóstico, uma ferramenta de auto avaliação para medir o grau de aderência da gestão ao modelo do PNQ. Corretamente aplicada, a ferramenta fornece um grau de maturidade da empresa nos níveis: Iniciante, Intermediário e Avançado. Também é possível obter sugestões de melhorias para os processos. Sua base está na aplicação de questões fundamentadas em sete critérios de excelência - portanto, há uma desatualização entre o modelo atual (2014) e a avaliação feita pelo software, gerada a partir do modelo de 2008. Ainda assim, sua contribuição segue relevante, ao propor uma pontuação com base nas respostas dadas às perguntas centrais do PNQ, calculando um percentual de atendimento para cada critério analisado e, ao final, informando o nível de excelência em gestão da empresa como um todo.

Foram realizadas três entrevistas com o principal responsável pela gestão da empresa. $\mathrm{Na}$ avaliação o pesquisador explicava para o entrevistado o critério avaliado e quais requisitos eram exigidos da organização. Para cada item o entrevistador questionava o entrevistado para identificar as práticas administrativas de aplicação do requisito, buscando por evidências concretas das práticas. Após esses questionamentos o resultado era lançado no software, que ao final informava a avaliação do critério.

\section{APRESENTAÇÃO DOS RESULTADOS}

A empresa Veículos Ltda. (nome real omitido), concessionária autorizada de uma montadora de veículos Top 5 no Brasil, atua no mercado de veículos novos, seminovos, peças, acessórios e assistência técnica, tendo sido criada na década de 1990, num estado da região sudeste. Cerca de 5 anos após sua fundação, num período de instabilidade, a concessionária foi adquirida por um grupo de empresários, os atuais diretores da organização. A filial, estabelecida numa cidade de médio porte e foco de pesquisa, foi inaugurada ao final do ano da aquisição e foi constituída parte por capital de seus sócios, parte financiada por recursos advindos da matriz.

No fim da década de 2000, após um processo de reestruturação física, passou a atender todos os padrões exigidos pela marca, oferecendo melhor ambiente a seus clientes, além de maior gama de produtos em estoque. Atualmente a filial é considerada de médio porte, devido ao seu faturamento bruto anual exceder a quantia de $\mathrm{R} \$ 16 \mathrm{MM}$ (dezesseis milhões de reais) de acordo com o BNDES. Do ponto de vista fiscal, a empresa trabalha sob regime RPA (Regime Periódico de Apuração), informando mensalmente os dados de sua movimentação para que sejam apurados os valores devidos relativos a impostos. A empresa vende cerca de 70 veículos novos por mês, e tem um bom relacionamento e comunicação com a montadora. 
Desse ponto em diante serão informados os critérios analisados através do software EMEG Diagnóstico 2007/2008, aplicados na empresa objeto de estudo, para cada um dos critérios do PNQ. Cada critério foi avaliado resultando numa porcentagem de aplicação, e também em reflexões por diagramas SWOT. Em cada caso uma pontuação de referência foi gerada, e uma proposta de ações implícita na colocação de fraquezas e oportunidades.

\subsection{LIDERANÇA}

Este critério examina como são exercidas a governança e a liderança, incluindo temas como o controle dos padrões de trabalho e aprendizado (FNQ, 2008). o líder orienta as ações, aperfeiçoa as competências individuais, obtendo o máximo de sua equipe sem infringir questões éticas ou motivacionais. Ele estabelece e cobra compromissos claramente definidos, disseminando as crenças e valores da organização. Um dos maiores desafios em ser líder é conduzir uma equipe onde todos trabalhem conjuntamente, desconsiderando as objeções individuais. Dentro de suas organizações os líderes devem ser capazes de dominar tecnologias complexas e gerir com eficácia o capital intelectual do qual dispõe. Isso exige que estejam convictos de que seu trabalho também seja significativo para as organizações às quais pertencem. Com base nas informações pesquisadas, foi possível calcular uma pontuação média para o critério Liderança (Figura 1).

Figura 1 - Pontuação do critério Liderança.

\begin{tabular}{|c|c|c|}
\hline \multicolumn{3}{|l|}{ Diagnóstico FNQ 2008} \\
\hline \multirow{2}{*}{\multicolumn{2}{|c|}{ Diagnóstico 100,00 \% respondido. }} & \multirow{11}{*}{ 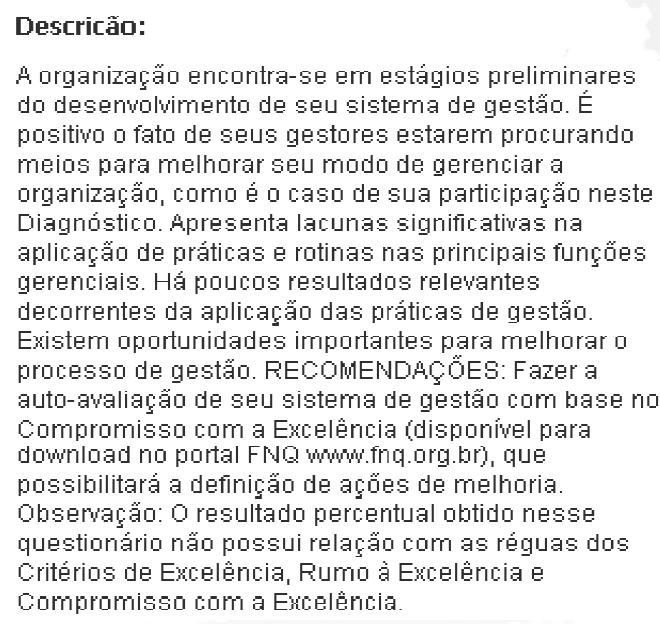 } \\
\hline & & \\
\hline Percentual Atingido: $18,50 \%$ & Faixa: Iniciante & \\
\hline \multicolumn{2}{|l|}{ Percentual Atingido por Critério } & \\
\hline LIDERANÇA & $17,05 \%$ & \\
\hline ESTRATÉGIAS E PLANOS & $20,83 \%$ & \\
\hline CLIENTES & $32,03 \%$ & \\
\hline SOCIEDADE & $0,00 \%$ & \\
\hline INFORMAÇÖES E CONHECIMENTO & $41,67 \%$ & \\
\hline PESSOAS & $5,00 \%$ & \\
\hline PRocessos & $20,59 \%$ & \\
\hline
\end{tabular}

Fonte: Autores, aplicando o software e-MEG Diagnóstico 2007/2008

A empresa está na faixa iniciante, obtendo $17 \%$, configurando estágio preliminar de desenvolvimento e necessitando de melhorias. Após a coleta de dados, aplicando a matriz SWOT em conversa com profissionais da empresa e especialistas em gestão, foram obtidos os 
resultados do Quadro 1. É um material que pode auxiliar na busca pela melhoria contínua, principalmente com ações focadas em itens identificados como pontos fracos e oportunidades.

\subsection{ESTRATÉGIAS E PLANOS}

Envolve a formulação e implementação das estratégias, com a análise do mercado de atuação e do macro ambiente, definição e controle de indicadores, desdobrados em metas e planos (FNQ, 2008). A vantagem competitiva da empresa depende da sua habilidade de formular estratégias que concretizem sua missão, visão e objetivos, garantindo sua perpetuidade. Com base nas informações pesquisadas, foi possível calcular uma pontuação média para o critério Estratégias e Planos (Figura 1). A empresa se encontra na faixa iniciante, obtendo o fator de $20 \%$, estando no estágio preliminar de desenvolvimento. Após a coleta de dados, aplicando a matriz SWOT foram obtidos os resultados do Quadro 2.

Quadro 1 - Matriz SWOT aplicada ao critério Liderança.

\begin{tabular}{|c|c|}
\hline $\begin{array}{l}\qquad \text { Pontos Fortes } \\
\text { - Ética nas relações comerciais } \\
\text { - Realização de análises de resultados } \\
\text { - Reuniões periódicas para discussão de } \\
\text { assuntos referentes ao processo chave - } \\
\text { vendas }\end{array}$ & $\begin{array}{l}\text { Pontos Fracos } \\
\text { - Os resultados da empresa são de acesso } \\
\text { restrito da alta admi nistração } \\
\text { - Estilo de liderança autocrático } \\
\text { - Formulação ineficiente da Visão, Missão e } \\
\text { Valores } \\
\text { - Rotatividade } \\
\text { - Conflitos pessoais } \\
\text { - Discordância dos colaboradores com o } \\
\text { estilo de liderança adotado }\end{array}$ \\
\hline $\begin{array}{l}\text { Ameaças } \\
\text { - Risco de perda de profissionais para } \\
\text { e mpresas concorrentes, devido ao estilo de } \\
\text { gestão desenvolvido na empresa } \\
\text { - Siste ma de gestão burocrático, o que } \\
\text { torna a re sposta da empresa lenta }\end{array}$ & $\begin{array}{l}\text { Oportunidades/Melhorias } \\
\text { - Reformular a visão e a missão da } \\
\text { empresa, divulgando-as } \\
\text { - Método para informar a equipe so bre os } \\
\text { resultados da empresa } \\
\text { - Criar docume nto formalizando regras e } \\
\text { valores éticos } \\
\text { - Elaborar métodos de de se rvolvimento e } \\
\text { que estimulem a liderança } \\
\text { - Descentralização do poder e adoção de } \\
\text { estilo de liderança de mocrático }\end{array}$ \\
\hline
\end{tabular}

Fonte: Autores

Quadro 2 - Matriz SWOT aplicada ao critério Estratégias e Planos. 


\section{Pontos Fortes}

- Monitoramento do ambiente externo

- Uso de indicadores para elaboração de metas

- Organização elabora estratégias e planos com a montadora

- Elaboração de planos de ação em conjunto com a montadora

\section{Ameaças}

- Falta de comunicação das estratégias, o que ocasiona lentidão nas reaçôes às mudanças do mercado

- Reação rápida dos concorrentes às estratégias criadas pela organização

Fonte: Autores

\section{Clientes}

Vê como a empresa interpreta o mercado, identificando e tratando as necessidades e expectativas dos clientes, fomentando seus relacionamentos e avaliando a satisfação (FNQ, 2008). O cliente gera receita para empresa, sendo fundamental sua conquista e manutenção. Para ele é que é gerado o valor, obtendo-se um retorno econômico em troca. Com base nas informações pesquisadas, foi possível calcular uma pontuação média para o critério Clientes (Figura 1). A empresa se encontra na faixa iniciante, obtendo o fator de $32 \%$, estando no estágio preliminar de desenvolvimento. Após a coleta de dados, aplicando a matriz SWOT foram obtidos os resultados do Quadro 3.

Quadro 3 - Matriz SWOT aplicada ao critério Clientes.
- Não apre senta foco no ambiente interno

- Deficiência de estratégias a longo prazo

- Falta de divulgação das estratégias aos colaboradores

- Não há divulgação dos planos de ações a tod as as partes intere ssadas

- Envolvimento da força de trabalho na divulgação das estratégias e planos da e mpresa

- Direcionar foco ao ambiente interno

- Criar estratégias de longo prazo

- Criar planos de ações consistentes e aplicados à realidade da organização 


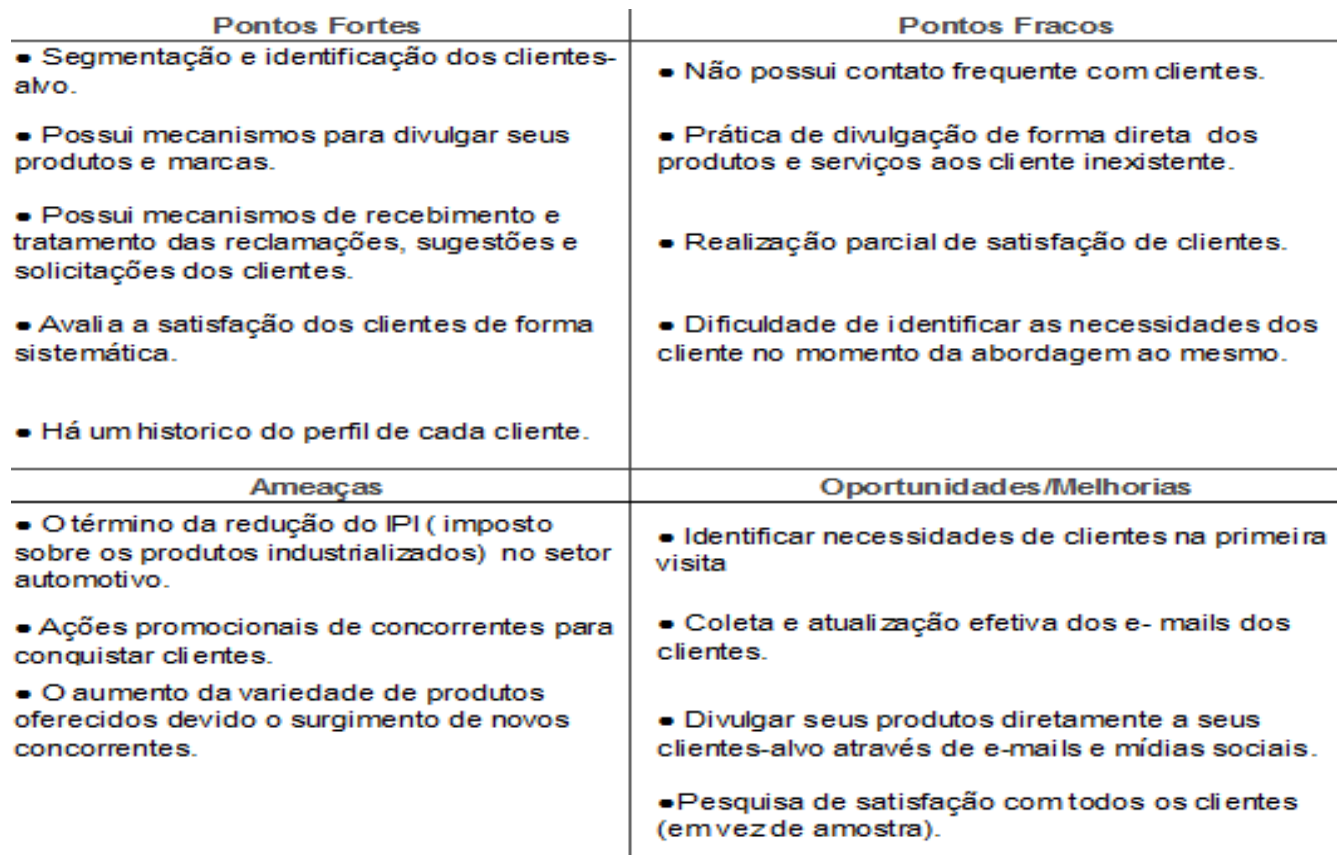

Fonte: Autores

\section{Sociedade}

Avalia ações para o desenvolvimento sustentável, tanto ambiental quanto social, incluindo projetos de alcance nacional, regional, local ou setorial (FNQ, 2008). Segundo o Instituto Ethos (2014) a responsabilidade social empresarial vem pela relação ética e transparente da empresa com seus públicos, impulsionando o desenvolvimento sustentável e preservando recursos ambientais e culturais. Assim, as empresas devem atender não somente aos interesses dos acionistas, mas também à comunidade da qual faz parte. Com base nas informações pesquisadas, foi possível calcular uma pontuação média para o critério Sociedade (Figura 1). A empresa não possui nenhum tipo de política, apenas ações isoladas, portanto seu percentual foi de $0 \%$. Após a coleta de dados, aplicando a matriz SWOT foram obtidos os resultados do Quadro 4. 
Quadro 4 - Matriz SWOT aplicada ao critério Sociedade.

\begin{tabular}{|c|c|}
\hline $\begin{array}{l}\text { Pontos F ortes } \\
\text { - Relação ética comfuncionários e } \\
\text { consumidores }\end{array}$ & $\begin{array}{l}\qquad \text { Pon tos Fracos } \\
\text { - Não possui uma política ambiental formal } \\
\text { - Não identifica seus impactos ambientais } \\
\text { - Não apoia a execução de projetos sociais } \\
\text { - Não há projetos de redução do uso de recursos } \\
\text { naturais } \\
\text { - Não há projetos de redução do consumo de } \\
\text { energia elétrica } \\
\text { - Não treina funcionários para questão ambiental }\end{array}$ \\
\hline $\begin{array}{l}\text { Ameaças } \\
\text { - Empresa semresponsabilidade social } \\
\text { - Imagem negativa perante o mercado }\end{array}$ & $\begin{array}{l}\text { Oportun idades/Melho rias } \\
\text { - Criação de um departamento ambiental ou } \\
\text { designação de um colaborador para realização das } \\
\text { tarefas relacionadas ao meio ambiente } \\
\text { - Identificação e minimização dos impactos } \\
\text { ambientais } \\
\text { - Conscientização da força de trabalho } \\
\text { - Participação em projetos sociais }\end{array}$ \\
\hline
\end{tabular}

Fonte: Autores.

\section{Informações \& Conhecimento}

Considera a gestão da informação, avaliando como a empresa compartilha, amplia e protege o seu conhecimento (FNQ, 2008). Inicialmente, faz-se necessário entendermos os conceitos de informação e conhecimento. Informações são dados, i.e. fatos ou observações que por si só são insuficientes para conter significado. Uma vez transpostos para um contexto significativo e útil, podem gerar conhecimento, que envolve a aplicação da informação. A busca de conhecimento é um elemento chave para o bom desempenho das empresas. Com base nas informações pesquisadas, foi possível calcular uma pontuação média para o critério Informações e Conhecimento (Figura 1). A empresa se encontra na faixa iniciante, obtendo o fator de $41 \%$, estando no estágio preliminar de desenvolvimento. Após a coleta de dados, aplicando a matriz SWOT foram obtidos os resultados do Quadro 5. 
Quadro 5 - Matriz SWOT aplicada ao critério Informações e Conhecimento.

Pontos Fortes

- Utilização do ERP

- Módulo do ERP exclusivo para ge stão da segurança das informações

- Várias ferramentas para comparação de informações

Pontos Fracos

- Falta de identificação dos ativos intangiveis

- Decisões incorretas to madas devido a qualidade das informações

- Conhecimento centrado nas mãos de poucos colaboradores

- Falta de uma politica documentada de segurança

\section{Ameaças}

- Monitoramento ativo das ações da concessionária por parte da concorrencia

- Maior percepção por parte da concorrencia em relação as mudanças do mercado

Fonte: Autores.

\section{Pessoas}

Examina os sistemas de trabalho da empresa, incluindo a seleção, contratação, organização, capacitação e desenvolvimento de pessoas. Também vê em que medida é construído um ambiente propício à qualidade de vida no trabalho (FNQ, 2008). Além dos investimentos em máquinas e matérias-primas é preciso dar ênfase a esse importante ativo, a força de trabalho, os talentos dotados de inteligência e capacidade de transformação, principal força motora nas organizações. Entre as variáveis da administração dos recursos humanos é preciso considerar a estrutura organizacional, o setor, o contexto, a tecnologia e as pessoas disponíveis. Com base nas informações pesquisadas, foi possível calcular uma pontuação média para o critério Pessoas (Figura 1). A empresa se encontra na faixa iniciante, obtendo o fator de 5\%, estando no estágio preliminar de desenvolvimento. Após a coleta de dados, aplicando a matriz SWOT foram obtidos os resultados do Quadro 6. 
Quadro 6 - Matriz SWOT aplicada ao critério Pessoas.

\section{Pontos Fortes}

- Mecanismos de identificação das necessidades de treinamento e capacitação

- Treinamentos periódicos
Pontos Fracos

- Estilo de liderança autocrática

- Falta de estímulo ao desenvolvimento

- Falta de estímulo à motivação

- Deficiência na identificação dos riscos ocupacionais

- Rotatividade e conflitos negativos

- Falta de fiscalização no uso de EPl's
Ameaças

- Perda de membros da força de trabalho para outras empresas, devido a oferecimento de benefícios, premiações, etc

\section{Oportunidad es /Melh orias}

- Incentivo ao desenvolvimento dos colaboradores

- Maior valorização do colaborador

- Incentivos e benefícios

- Política participativa

- Identificação efetiva dos riscos à saúde e tratamento das causas

Fonte: Autores.

\section{Processos}

Vê como a empresa identifica, gerencia, analisa e melhora seus processos (FNQ, 2008). Processos são atividades que toma uma entrada (recurso), adiciona valor (ação) e fornece uma saída para o cliente. As empresas são formadas por conjuntos de processos interligados, que precisam ser continuamente planejados, executados e aprimorados. Um processo chave é aquele diretamente relacionado à percepção do cliente, e deve ter prioridade. Com base nas informações pesquisadas, foi possível calcular uma pontuação média para o critério Processos (Figura 1). A empresa se encontra na faixa iniciante, obtendo o fator de $20 \%$, estando no estágio preliminar de desenvolvimento. Após a coleta de dados, aplicando a matriz SWOT foram obtidos os resultados do Quadro 7.

\subsection{PERCENTUAL ATINGIDO}

Os resultados são os efeitos das atividades produzidas pela empresa, mediadas por seu modelo de gestão (FNQ, 2008). Com base nas informações pesquisadas, foi possível calcular uma pontuação média para o critério Resultados (Figura 1). A empresa se encontra na faixa iniciante, obtendo o fator de $18 \%$, estando no estágio preliminar de desenvolvimento. 
Quadro 7 - Matriz SWOT aplicada ao critério Processos.

\begin{tabular}{|c|c|}
\hline $\begin{array}{l}\qquad \text { Pontos F ortes } \\
\text { - Padronização dos processos } \\
\text { - Moritoramento por indicadores } \\
\text { - Treiramento constante da força de trabalho } \\
\text { envolvida diretamerte nos processos } \\
\text { principais } \\
\text { - Utilização do ERP e do CRM } \\
\text { - Operacionalidade financeira }\end{array}$ & $\begin{array}{l}\text { Pontos F racos } \\
\text { - Baixo índice de parcrias com fomecedores } \\
\text { - Falta de documentação dos processos padronizados } \\
\text { - Baixo índice ou nulo de moritoramento dos processos } \\
\text { de apoio } \\
\text { - Baixo índice ou nulo de treinamertos aos colaboradores } \\
\text { envolvidos nos processos de apoio } \\
\text { - Cornecimento mal distribuído }\end{array}$ \\
\hline $\begin{array}{l}\text { Ameaças } \\
\text { - Falta de mão de obra qualificada no } \\
\text { mercado } \\
\text { - Crescimerto da concorrência } \\
\text { - Inovações na execução dos processos por } \\
\text { parte da concorrência }\end{array}$ & $\begin{array}{l}\text { Opo rtu nidades/Melhorias } \\
\text { - Monitoramento eficiente dos processos de apoio } \\
\text { - Capacitação dos colaboradores envolvidos nos } \\
\text { processos de apoio } \\
\text { - Documentar processos (Fluxograma) } \\
\text { - Disseminação do corhecimento } \\
\text { - Formular cadeia de suprimentos }\end{array}$ \\
\hline
\end{tabular}

Fonte: Autores.

Apesar de todos os pontos positivos identificados, vários dos critérios da FNQ obtiveram notas relativamente baixas, ou até mesmo nulas, indicando a necessidade de implantar ações de melhoria. Os critérios Clientes e Informações \& Conhecimento obtiveram os percentuais mais elevados, porém ainda necessitam de aprimoramento, pois por melhor que sejam não existe situação estática perfeita, que não possa ser melhorada. Os critérios Liderança, Estratégias e Planos \& Processos obtiveram percentual abaixo dos anteriores, porém apresentaram pontos positivos em alguns aspectos propostos. Já os critérios Sociedade \& Pessoas merecem grande atenção, pelo baixo percentual que mostra grande deficiência em fatores ligados ao diferencial e à vantagem competitiva da empresa. Assim, o sistema MEG da FNQ é de grande auxílio à melhoria da gestão, pois aponta de maneira efetiva virtudes e fraquezas, fornecendo referencias que podem auxiliar na melhoria da gestão, beneficiando a todas as partes envolvidas.

\section{CONSIDERAÇÕES FINAIS}

A excelência em gestão é determinante para alavancar o sucesso das empresas. Como parâmetro foi utilizado o modelo de excelência em gestão da FNQ para efetuar o diagnóstico, com resultados com pontuação geral média de $18 \%$ (28 pontos), implicando na avaliação de um nível de gestão ainda iniciante. Os pontos positivos foram a padronização de processos, e os processos de atendimento e abordagem de clientes, assim como as informações e seu gerenciamento, representando os critérios Processos, Clientes e Estratégias \& Planos. Os critérios que obtiveram as menores pontuações foram Pessoas, Sociedade e Liderança, porque 
a empresa não conta com políticas e estratégias visando o atendimento dos processos relacionados a esses critérios. Com a intenção de implementar melhorias e melhorar a pontuação foram sugeridas melhorias, utilizando o software e-MEG Autoavaliação 2007/2008, um meio para efetuar a análise da empresa, assim como os impactos das melhorias em seu planejamento estratégico.

Obteve-se um resultado de 59\% (89 pontos) como projeção do resultado a ser obtido com a execução das melhorias propostas à empresa. Foram propostas algumas práticas em cada um dos critérios, buscando associar os conceitos de melhoria contínua e desenvolvimento aos processos realizados. Pode-se concluir que a informação é um recurso importante na busca pelo sucesso. O levantamento das características da gestão atual fornece subsídios para implementação e manutenção de melhorias. O principal intuito é fornecer uma base para que as empresas possam perseguir e alcançar a excelência, potencializando seus esforços e buscando patamares cada vez maiores de sucesso e participação de mercado, obtendo o diferencial competitivo.

\section{REFERÊNCIAS}

CAMPOS, V. F. Gerenciamento da rotina do trabalho do dia-a-dia. $9^{a}$ Edição. Minas Gerais: INDG Tecnologia e Serviços, 2013.

CORRÊAA, H. L.; CORRÊAA, C. A. Administração de produção e operações: manufatura e serviços: uma abordagem estratégica. $2^{a}$ Edição. São Paulo: Atlas, 2013.

DEMING, W. Edwards. Out of the crisis. Cambridge, MA: Massachusetts Institute of Technology. Center for Advanced Engineering Study, v. 6, 1986.

FNQ - FUNDAÇÃO NACIONAL DA QAULIDADE. Cadernos Compromisso com a Excelência. São Paulo: Fundação Nacional da Qualidade. 2008.

Modelo de Excelengia da Gestão. 2014 - [citado em 2014 Out 8]. Disponível em: http://www.fnq.org.br/avalie-se/metodologia-meg/modelo-de-excelencia-da-gestao.

- Prêmio PNQ. $2014 \quad$ - [citado em 2014 Out 8]. Disponível em: http://www.fnq.org.br/avalie-se/pnq.

GALBRAITH, J. R. Designing organizations: An executive briefing on strategy, structure, and process. Jossey-Bass, 1995.

GONÇALVES, J. E. L. As empresas são grandes coleções de processos. $R A E$, v. 40, n. 1, p. 7 , 2000 .

INSTITUTO ETHOS. Modelo de Governança. 2014 - [citado em 2014 Nov 14]. Disponível em: http://www3.ethos.org.br/conteudo/governanca/modelo-de-governanca/\#. VJQtdl4CA. 
JURAN, J. M.; GRYNA, F. M. Controle da qualidade, São Paulo, SP: Makron, Books 1989. MORITA, A.; REINGOLD, E. M.; SHIMOMURA, M. Made in Japan: Akio Morita e a Sony. São Paulo: Livraria Cultura, 1986.

OLIVEIRA, G. T.; MARTINS, R. A.. Efeitos da adoção do modelo do Prêmio Nacional da Qualidade na medição de desempenho: estudos de caso em empresas ganhadoras do prêmio. Revista Gestão e Produção, v. 15, n. 2, p. 247-259, 2008.

PIGNANELLI, Alexandre. O Impacto da Adoção de Critérios de Excelência na Maximização da Riqueza dos Acionistas. Anais do IX SIMPOI, 2006.

YIN, R. K. Estudo de Caso - Planejamento e Método. 2. ed. São Paulo: Bookman, 2001. 